\title{
Proteomic Study of SUMOylation During Solanum tuberosum-Phytophthora infestans Interactions
}

\author{
Bertrand Colignon, ${ }^{1,2}$ Marc Dieu, ${ }^{2,3}$ Catherine Demazy, ${ }^{2,3}$ Edouard Delaive, ${ }^{2}$ Yordan Muhovski, ${ }^{1}$ \\ Martine Raes, ${ }^{2}$ and Sergio Mauro ${ }^{1,+}$ \\ ${ }^{1}$ Département Sciences du Vivant, Centre wallon de Recherches agronomiques, Gembloux, Belgium; ${ }^{2}$ URBC-NARILIS, \\ University of Namur, Belgium; and ${ }^{3}$ MaSUN, Mass spectrometry facility, University of Namur
}

Accepted 17 July 2017.

\begin{abstract}
Invasive plant pathogens have developed the ability to modify the metabolism of their host, promoting metabolic processes that facilitate the growth of the pathogen at the general expense of the host. The particular enzymatic process SUMOylation, which performs posttranslational modification of target proteins, leading to changes in many aspects of protein activity and, hence, metabolism, has been demonstrated to be active in many eukaryotic organisms, both animals and plants. Here, we provide experimental evidence that indicates that, in leaves of Solanum tuberosum that have been infected by Phytophthora infestans, the SUMO (small ubiquitin-like modifier) pathway enzymes of the host are partially under transcriptional control exerted by the oomycete. Using a recently developed approach that employs three-dimensional gels, we show that, during the infection process, the abundances of most of the known SUMO conjugates of $S$. tuberosum change significantly, some decreasing, but many increasing in abundance. The new proteomic approach has the potential to greatly facilitate investigation of the molecular events that take place during the invasion by a pathogen of its host plant.
\end{abstract}

Invasive plant pathogens have developed the ability to modify metabolic processes of their host and to promote those that facilitate their growth at the expense of the host. Successful pathogenesis also requires suppressing or counteracting the host defense system. In response, plants have evolved several lines of defense based on constitutive and inducible components. Constitutive defenses include preformed physical barriers, such as cell walls and waxy epidermal cuticles that act as passive defenses. Inducible defenses rest on the ability of plant cells to detect invading pathogens and then respond with inducible defenses (Senthil-Kumar and Mysore 2013). Plantinducible defenses comprise two distinct types: pathogenassociated molecular pattern (PAMP)-triggered immunity (PTI) and effector triggered immunity (ETI). The first of these, PTI, is activated following the detection of PAMPs (Boller and He 2009)

B. Colignon is a Fellow of the Belgian Fonds pour la Recherche dans l'Industrie et l'Agriculture (FRIA).

${ }^{\dagger}$ Corresponding author: S. Mauro; E-mail: mauro@cra.wallonie.be

*The $\boldsymbol{e}$-Xtra logo stands for "electronic extra" and indicates that one supplementary figure and two supplementary tables are published online.

This article is in the public domain and not copyrightable. It may be freely reprinted with customary crediting of the source. The American Phytopathological Society, 2017. by cell surface-localized pattern recognition receptors and the second, ETI, by the recognition of internal effectors (Thomma et al. 2011). These inducible defenses may result in a localized cell death (hypersensitive response [HR]), which is one of the major elements of plant defense (Jones and Dangl 2006). In addition, and complementary to the HR, plants also respond with the production of pathogen-toxic chemicals and pathogendegrading enzymes.

In response to these defenses by the plant, pathogens have evolved means of attenuating those defense mechanisms. Pathogens are able to secrete an array of effectors that interfere at various levels of the host plant's PTI and ETI mechanisms, leading to effector-triggered sensitivity. Our understanding of the molecular basis of these processes has recently been enhanced by systems biology-based approaches enabled by global metabolomic, proteomic, and transcriptomic analysis (Afroz et al. 2013; Aliferis et al. 2014; Lewis et al. 2015).

Posttranslational modifications (PTMs), such as glycosylation, phosphorylation, SUMOylation, or ubiquitinylation, provide a powerful mechanism to rapidly regulate and fine-tune protein functions in response to external or internal stimuli. During plantpathogen interactions, PTMs contribute to the activation of the immune response (Howden and Huitema 2012) but can also be appropriated by pathogens to turn off some of the plant defensive mechanisms (Kim et al. 2008; Lee et al. 2007; Park et al. 2011).

SUMOylation is an ATP-dependent enzymatic pathway involving PDM via i) the SUMO-activating enzyme (SAE) (which is composed of two subunits, SAE1 and SAE2) and ii) the SUMOconjugating enzyme (SCE). They covalently attach SUMO (small ubiquitin-like modifier) to a specific Lys residue of the target proteins, having a particular consensus sequence of amino acid residues " $\psi \mathrm{KXD} / \mathrm{E}$ " ( $\psi$, hydrophobic amino acid; K, Lys; X, any amino acid; D, aspartic acid; E, glutamic acid) (Novatchkova et al. 2004). The transfer of the mature SUMO to the SUMO acceptor Lys is facilitated by a third enzyme, SUMO-ligase. SUMOligase is also active in those reactions in which SUMOylation occurs at Lys residues outside of the consensus motif (Zhu et al. 2008). The actual level of SUMOylation level of particular target proteins is, furthermore, tightly regulated by deSUMOylases such as ESD4 (early in short days 4), which cleave the isopeptide bond between the SUMO fragment and its target (Novatchkova et al. 2004).

Among the first studies to draw attention to the relevance of SUMOylation in the mechanisms of plant-pathogen interactions are those of Hotson et al. (2003) and Roden et al. (2004). These authors showed that two effectors, XopD and AvrXv4, of the bacterial pathogen Xanthomonas campestris pv. vesicatoria disrupte SUMOylation in planta. 
In this work, we have used a newly developed three-dimensional (3D) sodium dodecyl sulfate-polyacrylamide gel electrophoresis (SDS-PAGE) procedure (Colignon et al. 2013) to investigate, first, whether the oomycete Phytophthora infestans compromises the SUMOylation pathway during pathogenesis of its host Solanum tuberosum and, then, to examine in detail how events along the SUMOylation pathway relate to the outcome of the interaction between Phytophthora infestans and Solanum tuberosum. For this, we used the cultivar Desiree, which is sensitive to P. infestans, together with the resistant variant 'Desiree/RB', which shares the same genetic background, except for the additional presence of the resistance gene Rpi-blbl, derived from the wild species Solanum bulbocastanum (Champouret et al. 2009; van der Vossen et al. 2003).

\section{RESULTS}

\section{Validation of the leaf infection process}

in $S$. tuberosum-P. infestans interactions.

To confirm that 'Desiree' and 'Desiree/RB' plantlets display a differential sensitivity to $P$. infestans $99-03 / 6(\mathrm{HT}), 18$-day-old plantlets were infected with a suspension of $P$. infestans sporangia and the leaf surfaces were then examined at regular intervals postinfection. Infected leaves of 'Desiree' developed necrotic spots at about $72 \mathrm{~h}$ postinfection (hpi). These spots later merged into large necrotic zones. Infected leaves of 'Desiree/ RB' developed only small necrotic spots and these remained localized to the infection site without further development. In order to confirm the differential sensitivity of the two genotypes to this strain of $P$. infestans, we monitored the expression of some gene markers that are known from previous work (discussed below) to be related either to the defense response of the host, viz. pathogenesis-related protein $1(P R I)$ and plastidic carbonic anhydrase $(C A)$, or to specific developmental stages of the pathogen, viz. fungal cellulose synthase 3 (CesA3) and haustorium-specific membrane protein (Pihmpl) (Avrova et al. 2008).

The host's PR1 is a salicylic acid (SA)-induced defense marker in potato (Eschen-Lippold et al. 2012). Although the role of the host's CA during plant pathogenesis is not, as yet, clearly defined, the level of expression of $C A$ during pathogenesis has been demonstrated to distinguish between potato cultivars known to be susceptible or resistant to $P$. infestans (Restrepo et al. 2005).

Following inoculation with $P$. infestans, the level of expression of PRI-1 increased strongly, reaching similar levels in infected leaves of each cultivar (Fig. 1A). However, in 'Desiree/ RB', the maximum level of expression was maintained for only a short time and, by $48 \mathrm{hpi}$, it had returned to the control level. In 'Desiree', the maximum level of expression of PR1-1 was not reached until $48 \mathrm{hpi}$ and thereafter returned to the control level.

As regards the expression of $C A$ in 'Desiree/RB', $C A$ levels reached a maximum at $12 \mathrm{hpi}$ and, then, decreased; in 'Desiree', the expression of $C A$ decreased throughout the observation period postinfection (Fig. 1B).

As regards the $P$. infestans genes, of the four cellulose synthase genes to have been characterized during appressorium formation, the level of expression of the most highly upregulated of the four, CesA3 (Grenville-Briggs et al. 2008), was at first similar in the two genotypes. The level then climbed to a maximum at $24 \mathrm{hpi}$ in 'Desiree' while it decreased progressively in 'Desiree/RB' (Fig. 1C).
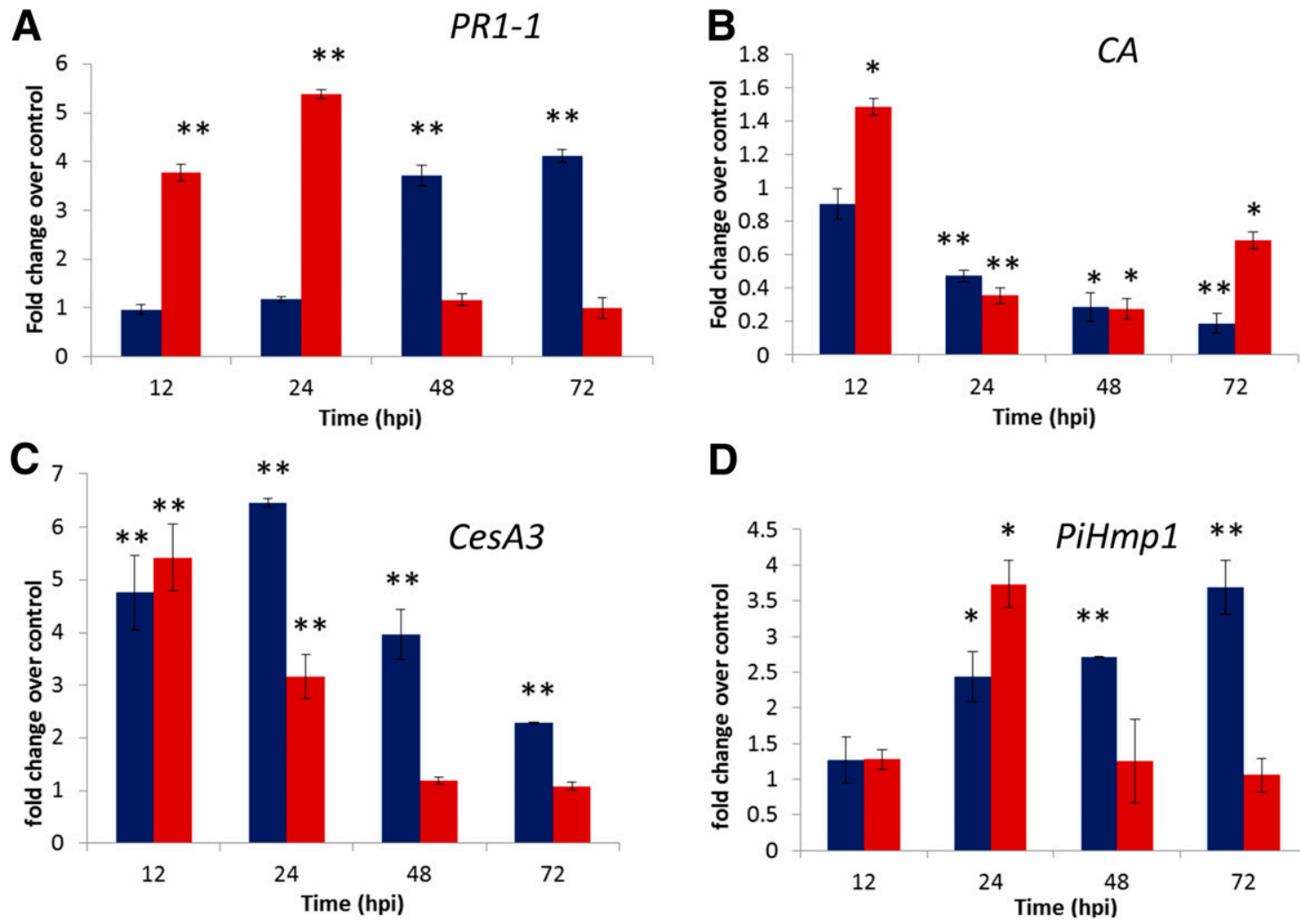

D

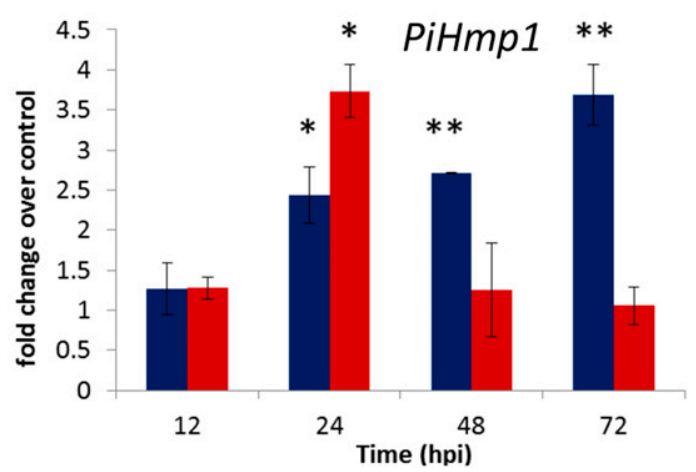

Fig. 1. Levels of expression of the selected marker genes as a function of time postinfection in Solanum tuberosum-Phytophthora infestans interactions. A, PR1-1, B, carbonic anhydrase $(C A), \mathbf{C}, C e s A 3$, and D, PiHmp1. Histograms represent the $N$ fold change of expression over uninoculated control. Columns on the right represent 'Desiree'(susceptible), columns on the left 'Desiree/RB' (resistant). Error bars represent \pm standard deviation of the mean $(n=3)$. The significance of the difference in the expression between treated and control as determined by Tukey's test is indicated bt asterisks (one asterisk [ $*$ ] for $P<0.05$, two asterisks $[* *], P<0.005)$. 
The second $P$. infestans gene, Pihmpl, gradually increased from 12 hpi onwards in susceptible cultivar Desiree while, in resistant variant 'Desiree/RB', the level reached a maximum at 24 hpi and thereafter declined (Fig. 1D).

The similarity of the expression levels of these two P. infestans genes during the first 24 hpi suggests that, initially, the development of $P$. infestans followed a similar pattern in the two genotypes, and this despite the very rapid activation of the SA-dependent defense mechanism in 'Desiree/RB'. After the first $24 \mathrm{~h}$, the level of expression in 'Desiree/RB' declined, suggesting that fungal growth had been arrested by the host. This was not observed in 'Desiree'.

Comparative time course expression profiling of SUMO enzymes by quantitative reverse transcription-polymerase chain reaction (qRT-PCR) in $S$. tuberosum-P. infestans interactions.

Having investigated some molecular aspects of the difference between resistant and susceptible genotypes, we then wished to determine whether or not $P$. infestans was able to modulate the expression of the SUMOylation pathway genes during the invasion of Solanum tuberosum. In order to examine the temporal pattern of SUMOylation pathway gene expression across various stages of $P$. infestans infection, a new and additional qRTPCR analysis was applied.

Although the potato genome is available (The Potato Genome Sequencing Consortium 2011), the SUMOylation machinery genes of $S$. tuberosum are not, as yet, completely described.
Therefore, we used nucleic acid alignments of genes of four other plant species, Arabidopsis thaliana, Solanum lycopersicum, Medicago truncatula, and Zea mays. Potato SUMOylation gene-specific primers for expression study were designed based on the conserved domains (data not shown). The PCR amplifications using potato cDNA and the selected potato genespecific primers showed amplicons of the expected size (data not shown). Primer specificity was validated using tenfold serial dilutions of cDNA. All primers displayed efficiencies between 94 and 99\% (data not shown).

The results of this work are summarized in Figure 2, which shows the altered expression profiles of the SUMOylation pathway genes during the course of infection. There was a statistically significant increase in the expression level of StSUMO1 in both genotypes for infection times $>12 \mathrm{hpi}$. This increase was more pronounced in 'Desiree/RB', in particular at 72 hpi (Fig. 2A). There was a bigger difference between 'Desiree' and 'Desiree/RB' in the results for transcript accumulation of SUMO-conjugating enzymes. In 'Desiree', the expression of $S A E 1 b$ and $S I Z 1$ decreased with time (Fig. $2 \mathrm{~B}$ and $\mathrm{E})$, while in 'Desiree/RB' the expression of these two components either remained more or less constant or increased with time throughout the experimental period. There was a transient, statistically significant increase in the expression level of $S A E 2$ in both genotypes at $12 \mathrm{hpi}$, at later times its expression level returned to the control values (Fig. 2C). By contrast, the expression level of $S C E$ increased in both genotypes and this increase occurred earlier and was more pronounced in
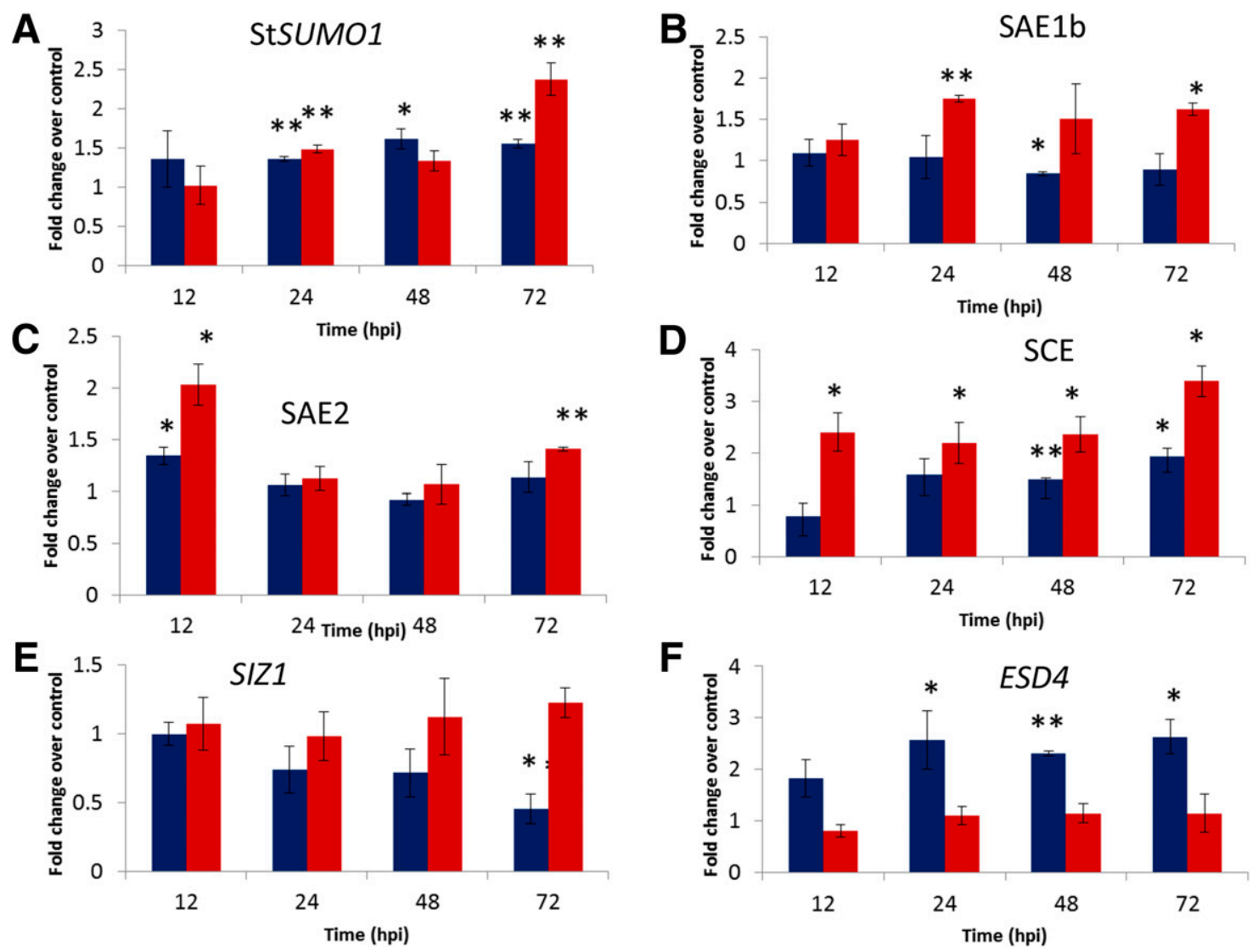

Fig. 2. Comparative expression of genes involved in the SUMOylation pathway as a function of time postinfection in Solanum tuberosum-Phytophthora infestans interactions. Gene expression was analyzed by quantitative reverse transcription-polymerase chain reaction. The histograms represent the $N$ fold increase in level of expression over the mock-inoculated corresponding control. Transcript abundance was monitored for following SUMO pathway components A, StSUMO1; B, SAE1b; C, SAE2; D, SCE; E, SIZ1; and F, ESD4. Columns on the left represent 'Desiree', columnson the right, 'Desiree/RB'. Error bars indicate \pm standard deviation of the mean $(n=3)$. The significance of the difference in the expression between treated and control samples, as determined by Tukey's test is indicated with asterisks (one asterisk [*] for $P<0.05$, two asterisks [**], $P<0.005$ ). 
'Desiree/RB' (Fig. 2D). The deSUMOylating enzyme ESD4 transcript was up-regulated in 'Desiree', while it remained constant in 'Desiree/RB' (Fig. 2F).

\section{Evolution of the abundance of StSUMO1/2 conjugates in both genotypes during potato leaf infection by $P$. infestans.}

To determine whether or not the altered changes in gene expression levels of the SUMOylation pathway were accompanied by similar changes in the StSUMO protein conjugates, total leaf protein extracts were analyzed and the levels of the endogenous StSUMO1/2 conjugates were determined. 1D SDS-PAGE gels were run, followed by Western blot analysis using an AtSUMO1/2 antibody (Supplementary Fig. S1). This enabled the global pattern of potato leaf StSUMO1/2 conjugate levels to be compared. In 'Desiree', we observed a decrease of both the free StSUMO1/2 polypeptides and of StSUMO1/2 conjugated proteins. The decrease was particularly marked at 48 hpi for StSUMO1/2 protein conjugates of molecular weight above $55 \mathrm{kDa}$. In 'Desiree/RB', the same measure of abundance of StSUMO1/2 targets reached a maximum at $12 \mathrm{hpi}$ and declined thereafter. This transient increase seemed to occur at the expense of the pool of free StSUMO1/2.

\section{Mapping of StSUMO1/2 conjugates on 3D gels.}

The above procedures did not allow precise identification of protein conjugates (1D gels have a limited resolution and Western-blotting is only a semiquantitative method). To overcome these limitations, a 2D approach was used to identify StSUMO1/2 protein conjugates in untreated leaves (Colignon et al. 2013). The low abundance of the StSUMO1/2 protein conjugates required that the protein samples be labeled with the highly sensitive fluorescent dye CyDIGE fluor Cy3 for scarce samples. StSUMO1/2 protein conjugates were visualized by preparative 2D SDS-PAGE followed by Western blot analysis. About 2,200 spots were detected in the 2D gels by the DeCyder software. Then the Western blot and 2D gel images were matched in order to detect and locate the StSUMO1/2 target proteins. In total, 69 immunoreactive spots could be matched with corresponding spots in the gel, allowing automated spot-picking in a duplicate gel (Fig. 3A and B).

Our first protein mass spectrometry (MS) identification experiments indicated, however, that many spots of interest contained more than one protein. This comigration made it impossible to identify the associated SUMO protein conjugates unambiguously. Therefore, the 3D approach developed by Colignon et al. (2013) was implemented to alleviate comigration-associated drawbacks and to provide the purity level required for unequivocal MS identification and measurements of statistically significant changes in StSUMO1/2 protein conjugate abundance between control and infected samples. This adapted protocol required three successive steps (Fig. 4).

In step 1, spots of interest, isolated as above, were then further fractionated by a third SDS-PAGE (3D) using a different gel buffer system. The use of two different buffer systems for SDS-PAGE enabled 2D spots to be resolved into their individual components (Colignon et al. 2013).

The resulting $893 \mathrm{D}$ spots were transferred onto polyvinylidene diflouride low-fluorescence (PVDF-LF) membranes and were submitted to a second round of Western blot analysis, using the antibody to AtSUMO1/2 (Fig. 4, step 1). This 3D electrophoretic fractionation offers enhanced resolution. It revealed that of the $893 \mathrm{D}$ spots, 71 contained StSUMO1/2 conjugates. Figure 3C shows the results of the 3D electrophoretic fractionation of $2 \mathrm{D}$ spots numbered 2,8 , and 37 . The procedure revealed that both $2 \mathrm{D}$ spots 2 and 8 contained two proteins, labeled "A" and "B" (Supplementary Tables S1 and $\mathrm{S} 2)$. In each case, only one of the pair proved to be positive for the anti-AtSUMO1/2 antibody (respectively, protein A in spot 2 and protein B in spot 8 ). The third spot in Figure 3C, spot 37, contained a single immuno-detected protein. A similar procedure was applied to all 89 spots, in order to apply the enhanced resolution that is conferred by $3 \mathrm{D}$ fractionation.

The second step of our improved 3D analysis was the quantification of the levels of StSUMO1/2 conjugates as a function of time postinfection in both genotypes, using a 3D difference gel electrophoresis (DIGE) analysis. The results indicated that the optimum period for comparison of SUMOylomes in the two genotypes would be $12 \mathrm{hpi}$, with an extra reading at $48 \mathrm{hpi}$ in the susceptible genotype 'Desiree'. As we did not find any difference between 'Desiree' and 'Desiree/RB' in the constitutive leaf SUMOylome (data not shown), we used the extract of mockinoculated leaf of 'Desiree' as control. We ran four 2D gels. Each gel contained a sample of leaf protein extract that had been labeled with $\mathrm{Cy} 3$ together with the internal standard (mix of equal amounts of each sample) labeled with Cy5. 2D spots of interest that had been previously identified in step 1 were picked in each of the four 2D gels. The four resulting gel pieces from each 2D spot were layered in four juxtaposed wells of the 3D gel. The subsequent 3D run resolved the 2D spots into their components (Fig. 5). Standard DIGE procedures were used to measure spot intensities and to normalize the intensities against the internal standard. For each 3D spot, the ratio "sample intensity/internal standard intensity" was calculated, and the ratios for each 3D spot were compared across all four samples (Fig. 5). The procedure was repeated three times and the mean value was calculated for each treatment. Figure 5 shows the results of this procedure for the $2 \mathrm{D}$ spot 8 . In the resistant genotype 'Desiree/RB', the levels of protein $\mathrm{A}$ increased postinoculation, while the abundance of protein $\mathrm{B}$, identified in step 1 as a StSUMO1/2 protein conjugate (Fig. 3C), decreased. The conclusion from Figure 5 is that, in the susceptible 'Desiree', postinfection levels of protein A decreased, reaching a minimum at $48 \mathrm{hpi}$, while levels of protein $\mathrm{B}$ increased postinfection.

The results of this analysis suggest that the abundance of StSUMO1/2 conjugates tends to increase during the incompatible interaction between pathogen and host. In the susceptible 'Desiree', our results clearly indicate that, for most of the SUMOylated proteins, the abundance of the SUMOylated form decreases, in particular at $48 \mathrm{hpi}$. This observation is in agreement with the earlier results using the $1 \mathrm{D}$ gels. However, our 3D DIGE analysis revealed a more complex regulation of SUMO conjugates. As an example, we showed that the SUMO1/2 target identified as the Vacuolar H+ ATPase A1 subunit (protein B in spot 8) was more abundant during infection in 'Desiree'. In summary, this second step gave us quantitative information on how the abundance of pre-existing endogenous SUMO1/2 conjugates is differentially impacted by the presence of $P$. infestans.

The third step of the adapted protocol was the identification, by tandem MS (MS/MS) and Gene Ontology (GO) biological process enrichment analysis, of the individual proteins involved in the SUMOylome processes following inoculation.

Therefore, a specific preparative 2D gel was performed and 2D spots of interest were picked and were further fractionated using 3D gels. To determine the identity of the SUMO1/2 conjugates, 89 3D spots were picked and their content was analyzed by liquid chromatography (LC) MS/MS (Fig. 4, step 3). Of the 66 identified proteins whose identity could be established by LC MS/MS, 58 were StSUMO1/2 conjugates, corresponding to 39 nonredundant conjugates.

In order to investigate the likely role of the SUMOylated proteins, a GO biological process enrichment analysis was performed using the Blast2Go bioinformatics tool. This showed (Fig. 6) that most of the 66 proteins are known to play a role in 
A

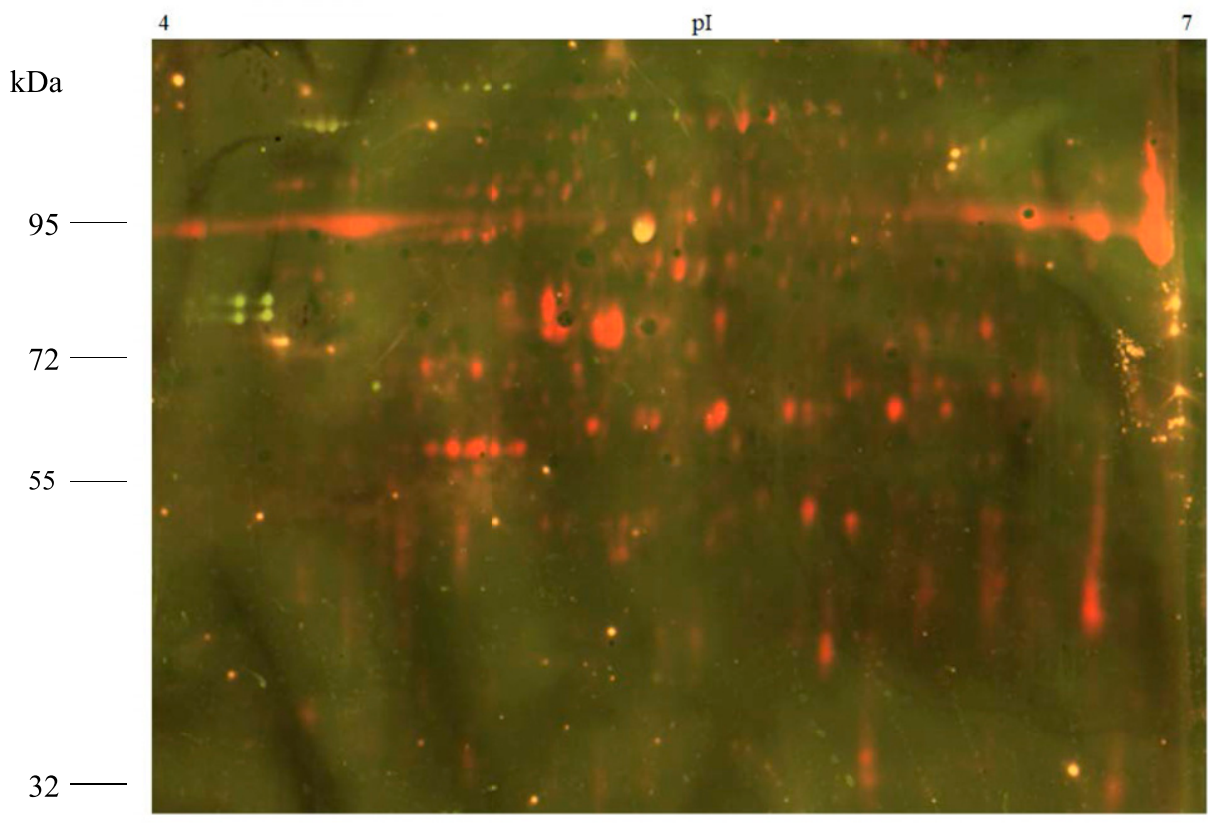

B $\mathrm{kDa}$

4

pI

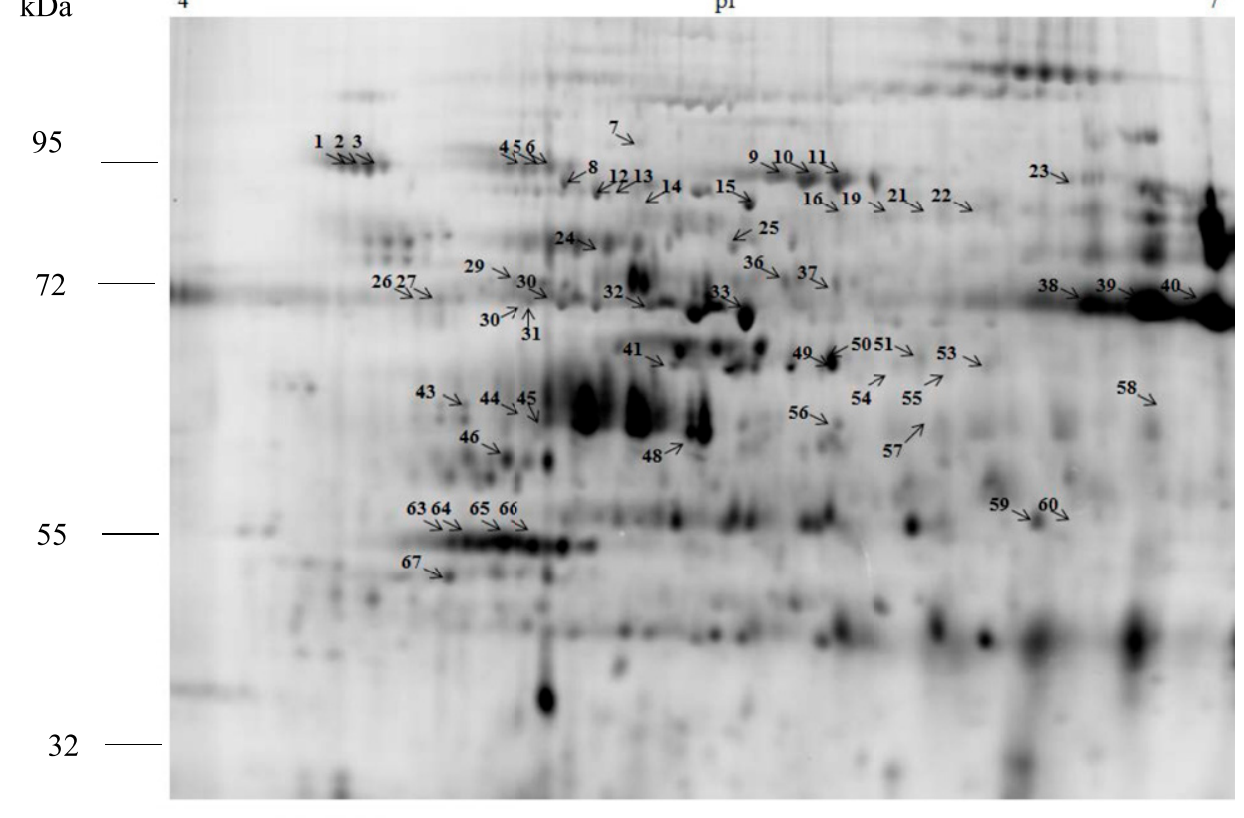

C

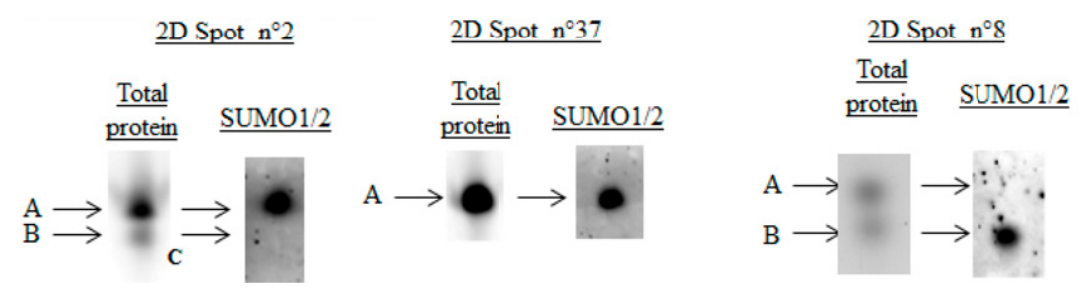

Fig. 3. Immunodetection of endogenous StSUMO1/2 conjugates in Solanum tuberosum leaves. A, Representative two-dimensional (2D) Western blot image. Proteins $(200 \mu \mathrm{g}$ ) were labeled with the $\mathrm{Cy} 3$ and were separated using isoelectric focusing (pH range 4.0 to $7.0,24 \mathrm{~cm}$ ) followed by $10 \%$ acrylamide sodium dodecyl sulfate-polyacrylamide gel electrophoresis with the Laemmli buffer system. Then the proteins were transferred onto a polyvinylidene diflouride lowfluorescence membrane and were probed with the anti-AtSUMO1/2 antibody. Visualization of antibody binding on 2D Western blots was achieved by appropriate Cy5-labeled secondary antibody. The fluorescence emission from Cy3-labeled total proteins and Cy5-labeled secondary antibody is superimposed. B, Representative grayscale gel image of the analysis. The immuno-reactive $2 \mathrm{D}$ spots are indicated by a highlighted number. The figure shows representative images of three independent experiments. Spots that were present in all three biological replicates were excised and were further analyzed. C, 3D gel images showing the results for three example spots following 3D electrophoretic fractionation on NuPage gels, in Tris acetate 7\% (Spots 2 and 8 ) or Bis-Tris glycine 4-12\% morpholineethanesulfonic acid buffer (Spot 37). After this additional electrophoretic fractionation, the 2D spots resolved into either 1 (Spot 37) or 2 elementary spots (Spots 2 and 8), which were visualized using a Typhoon 9400 imager. 
either photosynthesis, respiration, or defense processes. There was no statistically significant enrichment of SUMO conjugates in any particular process. Changes postinoculation in photosynthesis, hydrolase activity, and synthesis of amino acids occurred only in 'Desiree', while changes in lipid metabolism and processes involving binding of nucleic acids were observed only in 'Desiree/RB'.

The protein subcellular localization as predicted by the CELLO v.2.5 subCELlular LOcalization predictor showed that most of the SUMOylated proteins were chloroplast-associated.

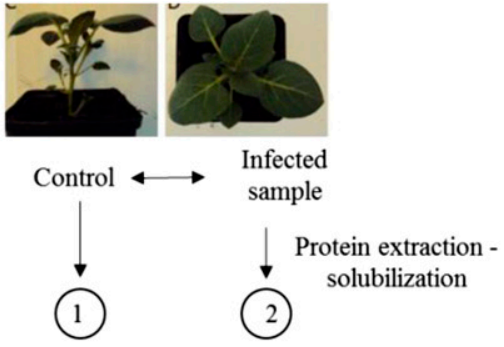

Step 1: resolution

Step 2: quantification

Labelling with saturation CyDye for analytical gel

preparative gel

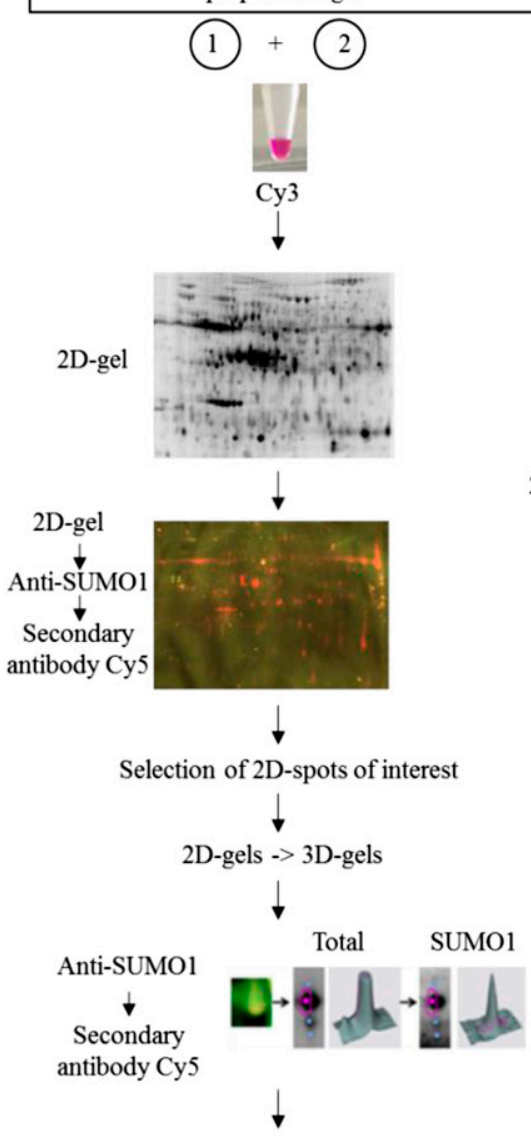

Selection of 3Dspots of interest

\section{Step 3: identification}

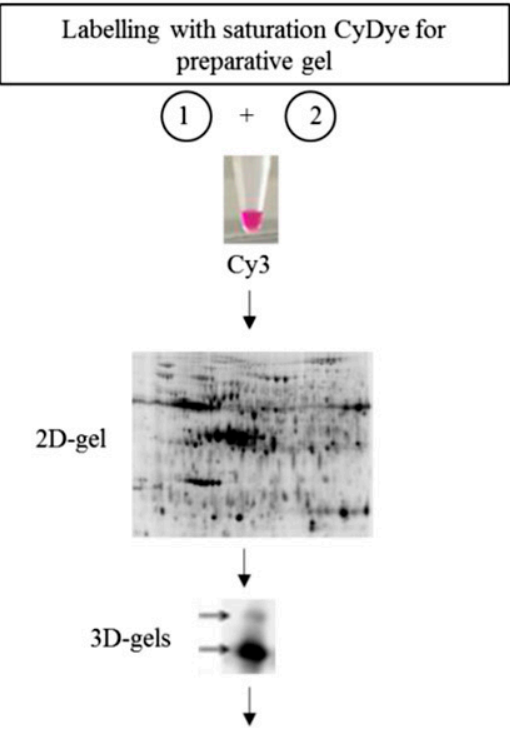

MS-MS analysis

Fig. 4. Flow chart of the analytical and preparative steps in SUMO-proteome analysis combining three-dimensional (3D) polyacrylamide gel electrophoresis (PAGE) and tandem mass spectrometry (MS/MS) analysis. Step 1: Extracted proteins labeled with the saturation CyDyes for analytical or preparative gels were separated with isoelectric focusing on an immobilized, $\mathrm{pH} 4.5$ to 7.0, gradient in the first dimension and sodium dodecyl sulfate (SDS)-PAGE in the second slab gel dimension, using the Laemmli buffer system. For the 3D step, spots of interest were further resolved on NuPage gel, either in Tris acetate 7\% or Bis-Tris glycine 4-12\% morpholineethanesulfonic acid buffer. The 3D gels were subsequently submitted to a second round of immunodetection, using the AtSUMO1/2 antibody so as to identify which of the 3D spots contained the StSUMO protein conjugate. Step 2: A comparative 2- and 3D difference gel electrophoresis (DIGE) analysis using the CyDye DIGE Fluor saturation dyes Cye 2 and Cye 3 was performed, in order to quantify changes in the relative abundance of the SUMOylated proteoforms during interactions. Spots of interest were excised from two 2D DIGE gels, with each gel containing one sample from the experiment and an internal standard (formed from equal amounts of every sample), and were submitted to the 3D electrophoretic fractionation. The spot fluorescence volume of each protein from the experiment was normalized to its corresponding spot fluorescence volume of the internal standard. The fold changes were the ratios of the normalized experiments to control spot fluorescence volumes. Step 3: Protein identification by liquid chromatography-MS/MS. Further preparative gels were prepared for analysis by MS choosing spots identified by the procedure described in step1. Each gel contained an equal protein amount of control and infected leaves. 


\section{DISCUSSION}

The technical aspects of this work include the use of a new 3D SDS-PAGE protocol to resolve and quantify changes in the endogenous SUMOylome during the infection of potato leaves by $P$. infestans, using two contrasted genotypes of potato. In order to unambiguously resolve and quantify changes in the leaf SUMOylome during infection, we have made significant improvements to the 3D gel electrophoresis fractionation protocol described earlier by Colignon et al. (2013). In addition, we have used qRT-PCR to investigate the changes in the expression of genes that encode for the enzymes of the SUMOylation pathway as a function of time and host genotype.

The background to this work is the growing body of evidence that both plant and animal pathogens have evolved to take control of, or at least to make use of, the host cell SUMOylation pathway and, thus, to facilitate the disease process. A number of animal models have now been elucidated. In Homo sapiens, the food poisoning bacteria Listeria monocytogenes generates a toxin, listeriolysin $\mathrm{O}$, that has been shown to disrupt the SUMOylation enzymatic cascade by promoting a proteasome-independent degradation of the SUMO conjugating enzyme Ubc9 (Ribet et al. 2010). The chicken embryo lethal orphan (CELO) adenovirus GAM1 produces a protein that leads to a dramatic decrease in the host's SUMO protein conjugates by inhibiting the activity of SAE. In other systems, promotion rather than disruption of SUMOylation may occur. For example, multiple SUMOylation of the second immediate-early protein Rta of Epstein-Barr virus by the host SUMOylation machinery enhanced the transactivating activity of Rta (Chang et al. 2004). Among bacterial plant pathogens, direct modulation of the SUMOylation pathway has been demonstrated for two Xanthomonas effectors, AvrXv4 and XopD. The Xanthomonas AvrXv4 effector was shown to decrease host SUMOylation levels when translocated into plant cells, and accordingly, it was suggested that AvrXv4 acts as a deSUMOylase (Roden et al. 2004). Later studies suggested, rather, that AvrXv4
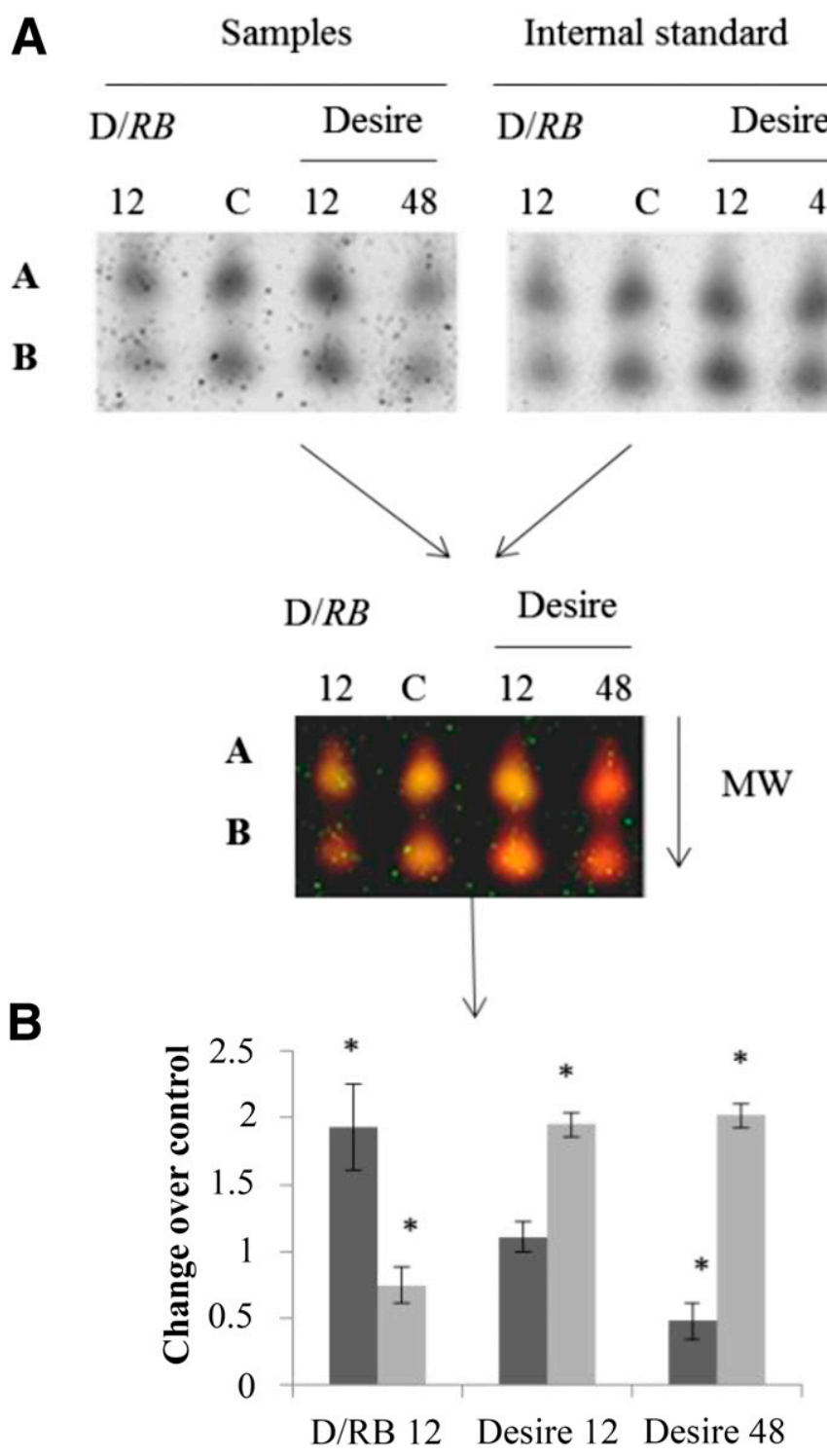

\section{Internal standard}
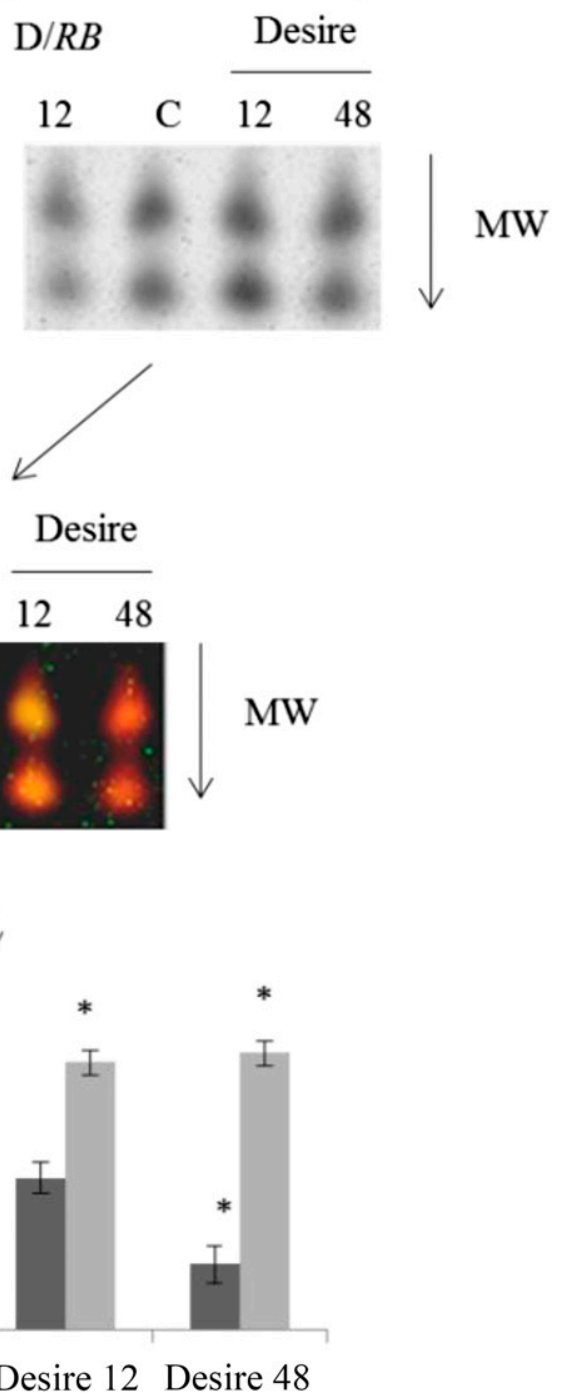

Fig. 5. Quantification of SUMOylated proteoforms abundance changes during infection by three-dimensional (3D) difference gel electrophoresis. The quantification is illustrated, for example, by $2 \mathrm{D}$ spot 8 . A, $2 \mathrm{D}$ spot 8 was excised from control (C) and infected leaves of 'Desiree' or 'D/Rb' at 12 and $48 \mathrm{~h}$ postinfection and was fractionated in a NuPage gel. After this additional electrophoretic fractionation, the 2D spots resolved into two elementary spots (A and B), which were visualized using a Typhoon 9400 imager. B, Quantification step shows an increase of abundance of A during the incompatible interaction while abundance of B decreases. In 'Desiree', the two 3D spots are down-regulated but present different dynamics. On the histograms, A is represented by the dark bar and B by the lighter gray bar. Significant differences in protein abundance are determined by Tukey's test (the asterisk [*] indicates $P<0.05$ ) with a minimum ratio of 1.5. All fluorescence volumes were estimated with the Decyder image analysis software. 
exerts an acetylase activity, thus blocking the SUMO acceptor Lys (Boch and Bonas 2001). The Xanthomonas type III effector XopD was demonstrated to deSUMOylate SUMO-conjugated proteins both in vitro and in planta (Hotson et al. 2003). Localization studies of XopD indicated that the site of action of XopD is the nucleus, while the site of action of AvrXv4 is the cytoplasm, supporting the contention that perturbation of the SUMOylome of different cellular compartments is a key mechanism of infection. Our data further extend this work and reveal new insights about the cellular mechanisms that operate during complex hostpathogen interaction. In our studies of the SUMOylation pathways in leaves of two closely related genotypes of potato when infected by potato blight, the data from qRT-PCR indicate, significant changes in both genotypes in the abundance of messenger RNA of components of the SUMOylation machinery. In the resistant genotype 'Desiree/RB', changes in the level of expression of the SUMO pathway genes were correlated with the increase in the global degree of protein SUMOylation (data from the 1D Western blot analysis). These changes in the expression pattern resulted from the rapid induction of all SUMOylation machinery gene components (except ESD4). The overall increase in SUMOylation was acompanied by an increase in the expression level of StSUMOI and reduction in free StSUMO. This suggests that the overall process may have been limited by the availability of StSUMO1.

We conclude, then, that the resistance of 'Desiree/RB' to infection by $P$. infestans depends, at least in part, on this cultivar ability to initiate a rapid generalized increase in SUMOylation activity as a response to infection. The evidence for such a mechanism has, until now, been rather scarce and contradictory. In Arabidopsis with a mutated SIZ1, conferring a reduction in the global level of SUMOylation resulted in an increased resistance to the bacterial pathogen Pseudomonas syringae pv. tomato DC3000 (Lee et al. 2007). By contrast, in Solanum peruvianum, reduced expression levels of SCE1 by virusinduced gene silencing resulted in an increased sensitivity (Esparza-Araiza et al. 2015). These sharply divergent conclusions may have been reached because only poorly resolved SUMO-conjugated protein profiles were compared. They could also reflect differences in either the pathogen lifestyle, infection strategies, or both (Chang et al. 2004; Ribet et al. 2010). In our system, there were the following significant differences in the patterns of expression of particular SUMO pathway genes expression over time. There was a rapid increase in the level of expression of ESD4 and, to a minor extent, of SCE and a somewhat delayed reduction in the expression of $S A E 1$ and of SIZ1. However, although this latter observation suggests a reduction in the degree of SUMOylation following inoculation, the reduction was observed for only a limited number of StSUMO protein conjugates. Furthermore, our proteomics analysis of events during the invasion of $S$. tuberosum by $P$. infestans revealed an even more complex picture. While the abundance of some particular StSUMO protein conjugates remained constant postinoculation, the abundance of certain other conjugates decreased and of yet others increased. There were also substantial differences between the two genotypes in the identities of these StSUMO protein conjugates. We accordingly suggest that the alteration of the host SUMOylome involves a number of different mechanisms that severally contribute to an acute resistance response in one genotype and to a rampant colonization of host tissue in the other. We suggest that the apparent lack of correlation between the changes in the expression level of the SUMO pathways genes and the changes in the abundance of some StSUMO protein conjugates might be related to the hemibiotrophic lifestyle of $P$. infestans, which may require that, during the biotrophic phase growth, the degree of SUMOylation of host proteins having central housekeeping functions is left unaffected while those pathways supporting the growth of the pathogen are modulated.

In support of this suggestion, we note that disruption of the SUMO E1-E2 interaction in transgenic Arabidopsis thaliana Col-0 resulted in a general depletion of the SUMOylation system and an increased sensitivity to the necrotrophic fungal pathogen Plectosphaerella cucumerina, which occurred without changes in the level of SUMO pathway genes expression (Castaño-Miquel et al. 2017). The authors considered that necrotrophic fungi could induce SUMOylation machinery depletion as a mechanism of pathogenicity.

We have also identified and quantified changes in the degree of SUMOylation of certain proteins that are not related to nuclear functions or to signaling pathways (van den Burg and Takken 2010). Almost all of these proteins are members of particular functional clusters, notably defense, photosynthesis, carbon, and energy metabolisms. These SUMOylated proteins indicate the engagement of host-specific metabolic reactions or pathways in response to $P$. infestans infection. Although SUMOylation has recently emerged as a major regulator system directing the majority of cellular activities, the molecular consequences of protein SUMOylation have not, as yet, been described in detail. However, it is well-established that the overall effects of SUMOylation are to modify the stability, localization, or activity of particular protein molecules and, also, to regulate interactions between particular protein molecules. Our observation that most of the StSUMO targets we have identified are related to one or other metabolic pathways that are associated with the chloroplast deserves particular attention, because components of the SUMOylation pathway have not previously been demonstrated in any cellular organelle outside the nucleus. Miteva et al. (2010) have already shown that the SUMOylation of proteins can act as a signal for protein degradation.

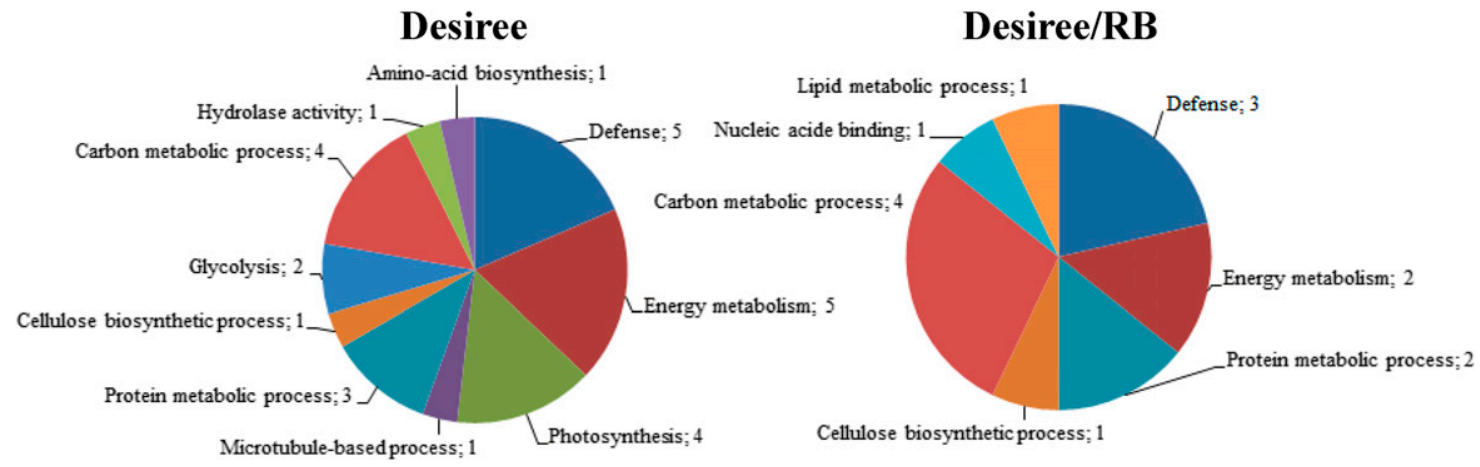

Fig. 6. Functional classification of identified proteins showing a variation of abundance by gene ontology term analysis. Only 27 StSUMO1/2 conjugates in 'Desiree' and 14 in 'Desiree/RB' showed a variation of their abundance during infection. The numbers correspond to the number of proteins in each category. 
We suggest that our observation of the SUMOylation of the chloroplast proteins addresses these proteins for degradation (Miteva et al. 2010) during a senescence-like process and its associated nutrient remobilization to support the demands for defense or on the contrary for the growth of pathogens (Häffner et al. 2015).

Further work is needed to fully understand the implications of our observation that the functional clusters glycolysis, hydrolase activity, microtubule-based processes, and aminoacid biosynthesis were activated in the interaction between $P$. infestans and the susceptible 'Desiree' but not in the resistant 'Desiree/RB'

In conclusion, it was shown that the levels of expression of all known elements of the SUMO pathway in leaves of $S$. tuberosum respond to $P$. infestans invasion in different ways; the abundance of some conjugates increases, while that of other conjugates declines. This suggests that several different regulatory mechanisms are operating to modulate the SUMOylation pathways. The 3D DIGE protocol we have optimized allows the identification and quantification of endogenous SUMO substrates in the physiological context of $S$. solanum-P. infestans interaction. We are confident that sample or subcellular fractionation, or both, will allow the detection and quantification of a higher number of SUMO protein substrates. Since roles of these StSUMO protein conjugates in the metabolism of $S$. tuberosum is not, as yet, understood in detail, further work will be required to get a full understanding of the role that each plays during the plant's response to pathogen invasion. We anticipate that this may come about thanks to further developments of SUMOylomics together with new approaches to protein-protein interactions (Finkelstein 2015). These should enable a full understanding of the role of the SUMO pathway in plant-pathogen interactions.

\section{MATERIALS AND METHODS}

\section{Plant material and infection.}

Plantlets of Solanum tuberosum L. 'Desiree' and 'Desiree/ RB' were first multiplied in vitro on Murashige and Skoog medium (pH 5.5) (Murashige and Skoog 1962) supplemented with $3 \%$ sucrose and $0.5 \%$ agar for 10 days. Plantlets were transplanted individually to a peat-based growing medium and were grown in controlled environment chambers with a 16-h day and 8-h night photoperiod (light intensity $=270 \mu \mathrm{mol} / \mathrm{m}^{2} \mathrm{~s}^{-1}$ ) at 21 and $18^{\circ} \mathrm{C}$, respectively, and $80 \%$ relative humidity. Threeweek-old plants were used in this experiment. The Phytophthora infestans strain Mont de Bary 99-03/6HT was cultivated on V8 culture medium, and sporangia were collected in water after 3 weeks. The apical leaflets of the second and third fully expanded leaves, counting from the terminal bud, were droplet-inoculated with a suspension containing approximately 1,500 sporangia per microliter Control plants were drop-inoculated in the same way, using water. The procedure aimed to cover the whole surface of the leaflet with droplets of approximately $15 \mu$ l. Inoculated leaves were collected 12 and 24 hpi in both genotypes. Extra collections at 48 and 72 hpi were performed for the susceptible 'Desiree'. Leaflets were immediately flash-frozen with liquid nitrogen. The control plants were treated in the same way and were kept under the same conditions, with due care to avoid cross inoculation. For each cultivar and timepoint, infected leaflets from four different plants were collected and pooled to produce one experimental sample. The whole procedure was repeated on three separate occasions (replicates).

\section{Plant protein extraction.}

Total protein of the liquid nitrogen-frozen $S$. tuberosum leaflets was extracted with trichloroacetic acid and acetone, following the procedure of Islam et al. (2004), and was solubilized in the following buffer: $8 \mathrm{M}$ urea, $2 \mathrm{M}$ thiourea, $4 \%$ $\mathrm{wt} / \mathrm{vol} \mathrm{CHAPS,} \% \mathrm{vol} / \mathrm{vol}$ immobilized $\mathrm{pH}$ gradient buffer and $40 \mathrm{mM}$ dithiothreitol. Final protein concentration was measured by the Bradford method (Bradford 1976).

\section{qRT-PCR expression analysis.}

Total RNA was extracted from control and infected 'Desiree' and 'Desiree/RB' leaflets by the TRIzol method (Life Technologies, Ghent, Belgium), according to the manufacturer's instructions. cDNA was synthesized from $5 \mu \mathrm{g}$ of total RNA, using random hexamers and RevertAid first strand cDNA synthesis kit (Life Technologies), according to the manufacturer's instructions. qRT-PCR analysis was performed using the CFX96 system (Bio-Rad). In order to produce PCR primers for each potato SUMO enzyme, corresponding coding genes from several species were aligned so as to identify conserved motifs among the sequences. These conserved motifs were used by Primer3 software to design gene-specific primers for quantifying the SUMOylation machinery transcripts in the qRT-PCR analysis (Table 1).

A set of potato $18 \mathrm{~S}$ rRNA primers was also designed for use as reference gene for normalization. The qPCR reactions were performed in a final volume of $25 \mu$ containing $2 \times$ Maxima SYBR green qPRC master mix (Life Technologies), $300 \mathrm{nM}$ of each direct and reverse gene-specific primer, and $50 \mathrm{ng}$ of cDNA template. After an initial activation of DNA polymerase at $95^{\circ} \mathrm{C}$ for $10 \mathrm{~min}$, samples were subjected to 40 cycles of amplification (denaturation at $95^{\circ} \mathrm{C}$ for $15 \mathrm{~s}$, annealing and extension together at $60^{\circ} \mathrm{C}$ for $1 \mathrm{~min}$ ). Control samples without cDNA were also included to check for any contamination or primer dimers. Immediately after the final PCR cycle, a melting curve analysis was performed to determine the specificity of the reaction by incubating the reaction at $95^{\circ} \mathrm{C}$ for $15 \mathrm{~s}$, annealing at $60^{\circ} \mathrm{C}$ for $20 \mathrm{~s}$, and then, slowly increasing the temperature, over the course of $20 \mathrm{~min}$, to $95^{\circ} \mathrm{C}$. To quantify the accumulation of transcripts, the comparative $\mathrm{Ct}$ (threshold cycle value) method of relative quantification $\left(2^{-\Delta \Delta \mathrm{Ct}}\right)$, as described by Livak and Schmittgen (2001), was applied. Tukey's range test was used to test the significance of the treatment effects. All statistical analyses were performed using the SYSTAT 8.0 package.

Table 1. Sequences of used primers $\left(5^{\prime}->3^{\prime}\right)$ in the quantitative reverse transcription-polymerase chain reaction expression analysis

\begin{tabular}{|c|c|}
\hline Gene & Primer sequence \\
\hline$S t S A E 1 b-D$ & TGT-CCA-TCT-TCG-ATG-CTG-AT \\
\hline$S t S A E 1 b-R$ & AAT-ATC-TCA-CCG-CAG-GAG-TCA \\
\hline StSUMO1-D & TAA-GGG-TCA-GGA-TGG-GAA-TG \\
\hline StSUMO1-R & CAG-GAG-TTT-GCT-CTG-CCC-TA \\
\hline StSAE2-D & TGC-AAG-AGC-TGG-TGT-CCA-CC \\
\hline$S t S A E 2-R$ & CGG-TTA-CTG-GTG-GCA-CAA-TTC \\
\hline StSiz1-D & CGG-TTG-GTG-ACC-GAA-GAT \\
\hline StSiz1-R & CAG-CAT-CGA-AGA-TGG-ACA-GA \\
\hline StSCE1-D & ACA-CTT-TGG-CGG-TTT-ACT-CG \\
\hline StSCE1-R & TTG-CTA-AGC-CGG-AGA-CAC-TT \\
\hline StESD4-D & CAA-TCG-GAG-AAA-GGT-TTT-GG \\
\hline StESD4-R & TCT-GGG-GTT-CCC-TTT-TCT-CT \\
\hline St18S-D & GTG-ACG-GGT-GAC-GGA-GAA-TT \\
\hline St18S-R & GAC-ACT-AAT-GCG-CCC-GGT-AT \\
\hline$S t C A-D$ & GCC-GAT-CAC-GGA-GAT-AAA-GA \\
\hline$S t C A-R$ & CTC-CCT-TCA-ATG-CCA-ATG-TT \\
\hline StPR1-1D & CTA-TCT-TGC-GGT-TCA-CAA-CG \\
\hline$S t P R 1-1 R$ & AGG-TTC-TCT-CCT-GCA-CCT-GA \\
\hline PiCesA3-R & ACG-TAG-TTC-CAC-GGG-TTC-GT \\
\hline PiCesA3-D & TTC-ACG-CTG-CTC-TTC-AGT-CAA \\
\hline PiHmpl-R & ACG-CCT-TGT-CCA-TCA-ACT-TC \\
\hline PiHmp1-D & CCG-CTA-ACT-TTG-CTC-TCA-CC \\
\hline
\end{tabular}




\section{Polyacrylamide gel-based protein fractionation.}

1D separation of proteins from total leaf extract was performed on $7.5 \%$ acrylamide gels using $50 \mu \mathrm{g}$ of protein extracts. Gels were run overnight, using the discontinuous Laemmli buffer system (Laemmli 1970). 2D gels were run as follows. A range of $\mathrm{pH} 4$ to 7 was used for the 24-cm-long isoelectric focusing strips, loaded onto $10 \%$ acrylamide 2D gels. These were run overnight using the Laemmli buffer system. In the case of 2D analytical gels for subsequent 3D DIGE analysis, $5 \mu \mathrm{g}$ of total protein was labeled, using the highly sensitive fluor dyes $\mathrm{Cy} 3$ and $\mathrm{Cy} 5$ for scarce samples (Amersham GE Healthcare, Munich, Germany), according to the manufacturer's protocol. Cy3 and Cy5 were used for, respectively, samples and the pooled standard. In the case of $2 \mathrm{D}$ gels for $2 \mathrm{D}$ Western-blot assays, $200 \mu \mathrm{g}$ of proteins were labeled using fluor Cy3 saturation dye. 2D gels for MS/MS analysis, a total of $300 \mu \mathrm{g}$ of proteins, were labeled as described by Colignon et al. (2013).

Three-dimensional DIGE was performed as described by Colignon et al. (2013). In brief, 2D spots of interest were excised, were layered in juxtaposed wells, and were re-electrophoresed on NuPage gels, in either Tris acetate 7\% or Bis-Tris glycine 4 to $12 \%$ morpholineethanesulfonic acid buffer (Life Technologies, Ghent, Belgium), according to their apparent molecular weight (Colignon et al. 2013). These gels were run using the protocol recommended by the manufacturer (Life Technologies).

\section{Western-blot assay.}

Following electrophoretic fractionation, gels for a Western-blot analysis were electroblotted onto the appropriate membrane. 1D gels were electroblotted onto a Hybond ECL membrane (Amersham GE Healthcare), using blotting buffer ( $25 \mathrm{mM}$ Tris$\mathrm{HCl}, 192 \mathrm{mM}$ glycine, 20\% [vol/vol] methanol). Membranes were blocked overnight at $4{ }^{\circ} \mathrm{C}$ in a $5 \%(\mathrm{wt} / \mathrm{vol})$ solution of skimmed milk powder in phosphate-buffered saline (PBS) (pH 7.4) containing $0.05 \%$ tween 20 . The same blotting buffer was used to transfer proteins from 2D and 3D gels onto a PVDF-LF blotting membrane (Amersham GE Healthcare). These membranes were blocked using a 5\% (wt/vol) solution of blocking agent (Amersham GE Healthcare) in PBS (pH 7.4) containing 0.05\% Tween 20.

For the detection of StSUMO1 conjugates, the polyclonal AtSUMO1 antibody from Agrisera (Vännäs, Sweden) was used. This antibody is predicted to detect AtSUMO1 and, also, AtSUMO2 in Arabidopsis thaliana and Solanum lycopsersicum.

Western blots were performed by incubating the membranes in PBS-Tween-milk and blocking agent buffer with specific polyclonal anti-AtSUMO1/2 antibodies (1:1,000 dilution) for $90 \mathrm{~min}$ at room temperature. Membranes were then washed several times and were reincubated with a secondary antibody for $90 \mathrm{~min}$ at room temperature. For 1D gels, the secondary antibody used was the horseradish peroxidase (HRP)-conjugated secondary antibody (Santa Cruz Biotechnology, Dallas) diluted 1: 2,000 in PBS-Tween-milk buffer. For 2D and 3D gels, the fluorescent secondary antibody coupled to Cy5 $(1: 2,000)$ (Jackson ImmunoResearch Europe Ltd, Suffolk, England) was used. Bound antibodies were detected using the Bløk-CH buffer for HRP chemiluminescence (Millipore Corp., Billerica, MA, U.S.A.) or by fluorescence imaging as described below.

As regards loading control, we used anti $\beta$ tubulin antibody (Jackson ImmunoResearch). PVDF-LF membranes were also stained with Ponceau S (Sigma, Saint Louis) in order to visualize the protein transfer.

\section{Image acquisition and analysis.}

Labeled proteins that had been separated by $2 \mathrm{D}$ and $3 \mathrm{D}$ gels were visualized using a Typhoon 9400 imager (Amersham GE
Healthcare) at wavelengths chosen to detect the two cysteinereactive cyanine fluorescent dyes. Cy3 images were scanned using a 532-nm laser with an emission filter of $580 \mathrm{~nm}$ and Cy5 images were scanned using a 633-nm laser and a 670-nm emission filter. In each case, the resolution was $100 \mu \mathrm{m}$. The resulting images were visualized using DeCyder 2D differential analysis software version 6.0 (Amersham GE Healthcare). Statistical analyses were performed with SAS 8.0 software (SAS Institute Inc., Cary, NC, U.S.A.). Variations that exceeded 1.5 -fold difference in means spot intensity between control and infected conditions are indicated by the software as significant at $P<0.05$.

\section{Enzymatic digestion, MS/MS analysis, and data analysis.}

Proteins were identified as detailed by Silvestre et al. (2010). For MS analysis, all 3D spots were picked and their protein content was analyzed, using a nano-LC electrospray ionization ESI)-MS/MS, the maXis UHR-TOF (Bruker, Bremen, Germany), coupled to a 2D-LC (Dionex UltiMate 3000) (Thermo Scientific, Geel, Belgium). The gel pieces were shrunk in $100 \%$ acetonitrile. The proteolytic digestion was performed by adding $3 \mu \mathrm{l}$ of modified trypsin (Promega, Leiden, The Netherlands) suspended in cold $100 \mathrm{mM} \mathrm{NH} \mathrm{HCO}_{3}$ buffer. Proteolysis was performed overnight at $37^{\circ} \mathrm{C}$. The supernatants were collected and kept at $-20^{\circ} \mathrm{C}$, prior to analysis. The digests were separated by reverse-phase LC using a $75-\mu \mathrm{m} \times 150-\mathrm{mm}$ reverse phase Dionex column (Acclaim Pep-Map 100 C18). Mobile phase A comprised 5\% acetonitrile and $95 \%$ aqueous solution of $0.1 \%$ formic acid. Mobile phase B was $0.1 \%$ formic acid in acetonitrile. One microliter of the digest was injected and the organic content of the mobile phase was increased linearly from 5 to $40 \% \mathrm{~B}$ in $40 \mathrm{~min}$ and from 40 to $100 \% \mathrm{~B}$ in $5 \mathrm{~min}$. The column effluent was connected to an ESI nano-sprayer (Bruker). In the survey scan, MS spectra were acquired for $0.5 \mathrm{~s}$ in the $\mathrm{m} / \mathrm{z}$ range between 50 and 2,200. The most intense peptide ions, $2+$ and $3+$, were sequenced. The CID energy was automatically set as a function of $\mathrm{m} / \mathrm{z}$ ratio and of the charge state of the precursor ion. Compass HyStar 3.2 software (Bruker) piloted the maXis and Dionex systems. DataAnalysis 4.0 (Bruker) created pick lists, and this file (xml format) was then used by ProteinScape 2.0 (Bruker). The program Mascot 2.2 was used as search engine (Matrix Science, London). The maximum number of missed cleavages per peptide was set at 1 . Methionine oxidation was set to "variable modification" and carbamidomethylation was set to "constant". The tolerance window for the mass of the monoisotopic peptide was $10 \mathrm{ppm}$ and the MS/MS tolerance window was fixed at $0.05 \mathrm{Da}$. The peak lists were compared with those in the National Center for Biotechnology Information nonredundant (NCBInr) database viridiplantae (691,659 sequences, downloaded on December 02, 2011 from the PlantGDB database. All MS/MS samples were analyzed using the Mascot software. Peptide identifications were accepted for those samples that had a minimal individual identity score greater than 30 . Protein identification was performed using the NCBInr database for all those samples having a score equal or greater than 60 .

\section{ACKNOWLEDGMENTS}

B. Colignon thanks Fonds pour la Recherche dans l'Industrie et l'Agriculture (FRIA) for the Ph.D. fellowship (FRIA, Brussels, Belgium). We also thank The Proteomic platform and the MaSUN Mass Spectrometry facility of the University of Namur (URBC-Narilis), who are supported by the FRS-FNRS (FNRS/FRFC 2.4619.09 and FNRS/FRFC 2.4.569.09F) and by the University of Namur. The authors thank R. G. F. Visser (Wageningen University, The Netherlands) for providing transgenic potato 'Desiree' plants containing $S$. bulbocastanum resistance gene Rpi-blbl and V. César for Phytophthora infestans 99-03/6HT. 


\section{LITERATURE CITED}

Afroz, A., Zahur, M., Zeeshan, N., and Komatsu, S. 2013. Plant-bacterium interactions analyzed by proteomics. Front. Plant Sci. 4:21.

Aliferis, K. A., Faubert, D., and Jabaji, S. 2014. A metabolic profiling strategy for the dissection of plant defense against fungal pathogens. PLoS One 9:e111930.

Avrova, A. O., Boevink, P. C., Young, V., Grenville-Briggs, L. J., van West, P., Birch, P. R., and Whisson, S. C. 2008. A novel Phytophthora infestans haustorium-specific membrane protein is required for infection of potato. Cell. Microbiol. 10:2271-2284

Boch, J., and Bonas, U. 2001. Gram-negative plant pathogenic bacteria Contrib. Microbiol. 8:186-196.

Boller, T., and He, S. Y. 2009. Innate immunity in plants: An arms race between pattern recognition receptors in plants and effectors in microbial pathogens. Science 324:742-744.

Bradford, M. M. 1976. A rapid and sensitive method for the quantitation of microgram quantities of protein utilizing the principle of protein-dye binding. Anal. Biochem. 72:248-254.

Castaño-Miquel, L., Mas, A., Teixeira, I., Seguí, J., Perearnau, A., Thampi, B.N., Schapire, A.L., Rodrigo, N., La Verde, G., Manrique, S., Coca, M., and Lois L.M. 2017. SUMOylation inhibition mediated by disruption of SUMO E1-E2 interactions confers plant susceptibility to necrotrophic fungal pathogens. Mol. Plant. 10:709-720.

Champouret, N., Bouwmeester, K., Rietman, H., van der Lee, T., Maliepaard, C., Heupink, A., van de Vondervoort, P. J., Jacobsen, E., Visser, R. G., van der Vossen, E. A., Govers, F., and Vleeshouwers, V. G. 2009. Phytophthora infestans isolates lacking class I ipiO variants are virulent on Rpi-blb1 potato. Mol. Plant-Microbe Interact. 22:1535-1545.

Chang, L. K., Lee, Y. H., Cheng, T. S., Hong, Y. R., Lu, P. J., Wang, J. J., Wang, W. H., Kuo, C. W., Li, S. S., and Liu, S. T. 2004. Post-translational modification of Rta of Epstein-Barr virus by SUMO-1. J. Biol. Chem. 279:38803-38812.

Colignon, B., Raes, M., Dieu, M., Delaive, E., and Mauro, S. 2013. Evaluation of three-dimensional gel electrophoresis to improve quantitative profiling of complex proteomes. Proteomics 13:2077-2082.

Eschen-Lippold, L., Landgraf, R., Smolka, U., Schulze, S., Heilmann, M., Heilmann, I., Hause, G., and Rosahl, S. 2012. Activation of defense against Phytophthora infestans in potato by down-regulation of syntaxin gene expression. New Phytol. 193:985-996.

Esparza-Araiza, M.J., Bañuelos-Hernández, B., Argüello-Astorga, GR., Lara-Ávila, J.P., Goodwin, P.H., Isordia-Jasso, M.I., Castillo-Collazo, R., Rougon-Cardoso, A., Alpuche-Solís, Á.G. 2015. Evaluation of a SUMO E2 conjugating enzyme involved in resistance to Clavibacter michiganensis subsp. michiganensis in Solanum peruvianum, through a tomato mottle virus VIGS assay. Front Plant Sci. 6:1019.

Finkelstein, J. M. 2015. Connecting the dots. Nat. Chem. Biol. 11:449.

Grenville-Briggs, L. J., Anderson, V. L., Fugelstad, J., Avrova, A. O., Bouzenzana, J., Williams, A., Wawra, S., Whisson, S. C., Birch, P. R., Bulone, V., and van West, P. 2008. Cellulose synthesis in Phytophthora infestans is required for normal appressorium formation and successful infection of potato. Plant Cell 20:720-738.

Häffner, E., Konietzki, S., and Diederichsen, E. 2015. Keeping control: The role of senescence and development in plant pathogenesis and defense. Plants Basel 4:449-488.

Hotson, A., Chosed, R., Shu, H., Orth, K., and Mudgett, M. B. 2003. Xanthomonas type III effector XopD targets SUMO-conjugated proteins in planta. Mol. Microbiol. 50:377-389.

Howden, A. J., and Huitema, E. 2012. Effector-triggered post-translational modifications and their role in suppression of plant immunity. Front. Plant Sci. 3:160.

Islam, N., Lonsdale, M., Upadhyaya, N. M., Higgins, T. J., Hirano, H., and Akhurst, R. 2004. Protein extraction from mature rice leaves for twodimensional gel electrophoresis and its application in proteome analysis. Proteomics 4:1903-1908.

Jones, J. D., and Dangl, J. L. 2006. The plant immune system. Nature 444: 323-329.

Kim, J. G., Taylor, K. W., Hotson, A., Keegan, M., Schmelz, E. A., and Mudgett, M. B. 2008. XopD SUMO protease affects host transcription, promotes pathogen growth, and delays symptom development in xanthomonas-infected tomato leaves. Plant Cell 20:1915-1929.
Laemmli, U. K. 1970. Cleavage of structural proteins during the assembly of the head of bacteriophage T4. Nature 227:680-685.

Lee, J., Miura, K., Bressan, R. A., Hasegawa, P. M., and Yun, D. J. 2007. Regulation of plant innate immunity by SUMO E3 ligase. Plant Signal. Behav. 2:253-254.

Lewis, L. A., Polanski, K., de Torres-Zabala, M., Jayaraman, S., Bowden, L., Moore, J., Penfold, C. A., Jenkins, D. J., Hill, C., Baxter, L. Kulasekaran, S., Truman, W., Littlejohn, G., Prusinska, J., Mead, A., Steinbrenner, J., Hickman, R., Rand, D., Wild, D. L., Ott, S., BuchananWollaston, V., Smirnoff, N., Beynon, J., Denby, K., and Grant, M. 2015. Transcriptional dynamics driving MAMP-triggered immunity and pathogen effector-Mediated Immunosuppression in Arabidopsis leaves following infection with Pseudomonas syringae pv. tomato DC3000. Plant Cell 27:3038-3064.

Livak, K. J., and Schmittgen, T. D. 2001. Analysis of relative gene expression data using real-time quantitative PCR and the $2^{-\Delta \Delta(\mathrm{C}(\mathrm{T})}$ method. Methods 25:402-408.

Miteva, M., Keusekotten, K., Hofmann, K., Praefcke, G. J., and Dohmen, R. J. 2010. Sumoylation as a signal for polyubiquitylation and proteasomal degradation. Subcell. Biochem. 54:195-214.

Murashige, T., and Skoog, F. 1962. A revised medium for rapid growth and bioassays with tobacco cultures. Plant Physiol. 15:473-497.

Novatchkova, M., Budhiraja, R., Coupland, G., Eisenhaber, F., and Bachmair, A. 2004. SUMO conjugation in plants. Planta 220:1-8.

Park, H. J., Kim, W. Y., Park, H. C., Lee, S. Y., Bohnert, H. J., and Yun, D. J. 2011. SUMO and SUMOylation in plants. Mol. Cells 32:305-316.

The Potato Genome Sequencing Consortium. 2011. Genome sequence and analysis of the tuber crop potato. Nature 475:189-195.

Restrepo, S., Myers, K. L., del Pozo, O., Martin, G. B., Hart, A. L., Buell, C. R., Fry, W. E., and Smart, C. D. 2005. Gene profiling of a compatible interaction between Phytophthora infestans and Solanum tuberosum suggests a role for carbonic anhydrase. Mol. Plant-Microbe Interact. 18:913-922.

Ribet, D., Hamon, M., Gouin, E., Nahori, M. A., Impens, F., Neyret-Kahn, H., Gevaert, K., Vandekerckhove, J., Dejean, A., and Cossart, P. 2010. Listeria monocytogenes impairs SUMOylation for efficient infection Nature 464:1192-1195.

Roden, J., Eardley, L., Hotson, A., Cao, Y., and Mudgett, M. B. 2004 Characterization of the Xanthomonas AvrXv4 effector, a SUMO protease translocated into plant cells. Mol. Plant-Microbe Interact. 17:633-643.

Senthil-Kumar, M., and Mysore, K. S. 2013. Nonhost resistance against bacterial pathogens: Retrospectives and prospects. Annu. Rev. Phytopathol. 51:407-427.

Silvestre, F., Huynh, T. T., Bernard, A., Dorts, J., Dieu, M., Raes, M., Nguyen, P. T., and Kestemont, P. 2010. A differential proteomic approach to assess the effects of chemotherapeutics and production management strategy on giant tiger shrimp Penaeus monodon. Comp. Biochem. Physiol. Part D Genomics Proteomics 5:227-233.

Thomma, B. P., Nürnberger, T., and Joosten, M. H. 2011. Of PAMPs and effectors: The blurred PTI-ETI dichotomy. Plant Cell 23:4-15.

van den Burg, H. A., and Takken, F. L. W. 2010. SUMO-, MAPK-, and resistance protein-signaling converge at transcription complexes that regulate plant innate immunity. Plant Signal. Behav. 5:1597-1601.

van der Vossen, E., Sikkema, A., Hekkert, Bt., Gros, J., Stevens, P., Muskens, M., Wouters, D., Pereira, A., Stiekema, W., and Allefs, S. 2003. An ancient $R$ gene from the wild potato species Solanum bulbocastanum confers broad-spectrum resistance to Phytophthora infestans in cultivated potato and tomato. Plant J. 36:867-882.

Zhu, J., Zhu, S., Guzzo, C. M., Ellis, N. A., Sung, K. S., Choi, C. Y., and Matunis, M. J. 2008. Small ubiquitin-related modifier (SUMO) binding determines substrate recognition and paralog-selective SUMO modification. J. Biol. Chem. 283:29405-29415.

\section{AUTHOR-RECOMMENDED INTERNET RESOURCES}

The Blast2Go bioinformatics tool: https://www.blast2go.com The NCBInr database: https://www.ncbi.nlm.nih.gov/refseq/ The PlantGDB database: http://www.plantgdb.org/download/download.php Primer3 software: http://frodo.wi.mit.edu 